\title{
Development of Neural Network Model to Classify Women Carrying Water Jobs in Terms of Physiological Risk
}

\author{
Rohit Sharma \\ Faculty of Engineering \\ DEI, Dayalbagh \\ Agra, UP, India
}

\author{
Ranjit Singh \\ Faculty of Engineering \\ DEI, Dayalbagh \\ Agra, UP, India
}

\begin{abstract}
Women carrying water generally considered to be a profession with high level of physical stress that tend to increase and lead to a high risk of MSDs. So, the objective of this study was to develop an Artificial Neural Network (ANN) based diagnostic model which can classify water carrying jobs according to the potential risk of physiological stress. ANN models method of predicting outcomes, which are gradually finding their way into the safety field. Limited studies have shown that they are capable of predicting outcomes more accurately than statistical analysis. Back Propagation algorithm with LM training was used in this study to train the ANN architecture and same has been tested for the various data sets. The data sets used in this research was collected from the physiological study of WCW. This research work demonstrates that the developed ANN model exhibits good performance in prediction of physiological stress in high and low risk categories. This model provides a higher proportion of correct classification than other previous models. So, the system can be useful in injury prevention due to manual carrying of loads.
\end{abstract}

\section{General Terms}

Bio-informatics, Artificial Neural Network

\section{Keywords}

Women Carrying Water, MSDs, Physiological risk, Artificial Neural Network

\section{INTRODUCTION}

Humans are all alike in facing the basic constraint of time and in needing water to drink every day. As well, water is needed for drinking, sanitation, bathing and food preparation. Adding all water needs together, the United Nations High Commissioner for Refugees [20] suggests that 15 litres per person per day is required while the Human Development Report of UNDP sets a standard of 20 litres per capita per day, and Gleick [10] argues for a higher minimum 50 litres (approximately) per day per person. Whatever the exact level of this basic need, the residents of developed countries (and the majority of Indian citizens) can simply turn the tap and satisfy it immediately, but in approximately $18.6 \%$ of rural Indian households somebody (usually female) has to spend an average of 47 minutes per day in fetching water for fulfilling their basic water needs.

Traditionally, fetching water has been a woman's job. It does not matter if the women are old, young or pregnant, crucial household needs have to be met after weary day. For women there are no developed countries, they work for longer hours, the plight of poor rural women is rather worse. Every dawn brings with it a long search of fuel fodder and water. They generally fetch 15 to 20 litres of water in one time from a source within 1 kilometer of the user's dwelling" and fetch up to 80 litres of water for fulfilling their and family needs. Fetching and carrying water is women's work in rural India. In the villages of the desert district of Banaskantha, women spend up to six hours a day bringing water from distant sources to their homes. They carry about 20 to 30 liters on their heads on each trip, often walking barefoot [14]. In Haryana where all the villages are provided with safe drinking water through community water supply since 1990 , fetching water was found drudgery prone activity [11]. In the year 1999-2000, AICRP (All India coordinated research project) team of FRM conducted ergonomic evaluation of fetching water with the objective to see the risk involved in this activity. Fetching water is an extremely strenuous activity undertaken by rural women and it consumes an enormous amount of their time and energy and reduces it for the rest of work.

Physical loading of the body within an individual's capacity for adaptive responses may lead to tissue strengthening, however, frequent loading beyond capacity for adaptation or repair may lead to injury through fatigue failure, accumulation of fatigue damage [1] or early degenerative changes in bone and soft tissues [11,9]. However, water carrying is a physical activity and carrying heavy loads for prolonged periods covering long distance put the postural muscles under continuous contraction leading to muscular fatigue and resulted into sever musculoskeletal injuries such as spinal pain or other joint problems $[9,23]$. A woman feels more evident pain while carrying load back home, such as in neck, upper arm, shoulder joints, upper leg, lower back and calf. Such assumptions are supported by strong evidence that the physical demands of work such as handling heavy materials, bending, twisting and lifting, are risk factors for onset of simple low back pain [1] and other musculoskeletal disorders $[4,6]$. A woman also feels very sever to severe pain in shoulder joints, upper back and lower arm especially while drawing water. However, very few studies have specifically investigated water carrying as it is performed by women in developing countries and used appropriate methodologies to investigate its association with health generally or musculoskeletal disorders specifically [21]. Some women may experience high rates of perceived exertion and pain sufficient to limit their capacity to carry water containers [15]. Reduced capacity of women to collect water due to pain or fatigue may have serious implications for the health of their families. 


\section{OBJECTIVE OF STUDY}

The main objective of the study was to perform the physiological study among the women carrying water in villages of Haryana for checking the physiological stress in different modes of load carrying and also to develop an artificial neural network based diagnostic system which could classify the jobs of WCW in physiological high and low risk. Such an expert system would be very useful in preventing accidents or injuries to WCW, who are not aware about the ill effects of carrying loads.

\section{METHODOLOGY}

\subsection{Physiological Study}

\subsubsection{Data collection}

A sample of 20 women subjects aged (30.2 \pm 8.3$)$ were selected at random from the villages of Kaithal District, Haryana; their basic data are presented in Table 1. LBW and PI were calculated from anthropometric measurements of the subjects $(24.2 \pm 6.8 ; 23.4 \pm 1.6)$. Information regarding B.P., hemoglobin content was also recorded for checking the physical fitness of the WCW. The subjects were informed of the purpose and procedures of the study and consented to participate.

Table 1. Physical Characteristics of the women carrying water

\begin{tabular}{|l|c|c|}
\hline \multirow{2}{*}{ Variable } & \multicolumn{2}{|c|}{ Women carrying water } \\
\cline { 2 - 3 } & Mean & SD \\
\hline Age $(\mathrm{yr})$ & 30.2 & \pm 8.3 \\
\hline Weight $(\mathrm{kg})$ & 50.4 & \pm 10.7 \\
\hline Height $(\mathrm{cm})$ & 150.2 & \pm 5.2 \\
\hline Fat $(\%)$ & 24.6 & \pm 5.8 \\
\hline Lean body weight $(\mathrm{kg})$ & 24.2 & \pm 6.8 \\
\hline Ponderal index & 23.4 & \pm 1.6 \\
\hline
\end{tabular}

Significant differences $(\mathrm{p}<0.001)$ were observed in the body weight, body fat, and lean body weight among the WCW. Based on the PI values, fat content and LBW, it can be inferred that the body build of the WCW were more towards meso-endomorphic type.

\subsubsection{Dietary intake of women carrying water $(W C W)$}

The WCW consumes less calorie intake per day. But as their whole day job is mostly sedentary in nature, except for the morning water carrying activity which was calculated from the random samples. Higher fat content for the WCW is evident. The average hemoglobin content of WCW was 12 gm\% ( $\mathrm{SD} \pm 1.38$ ) which was closer to the normal population. The lower calorie intake might be the reason for the poor physical fitness of the WCW.

Table 2. Percentage of women habituated in different modes of water carrying.

\begin{tabular}{|l|c|}
\hline Mode & Percentage of mode (\%) \\
\hline Head & 51.7 \\
\hline Shoulder & 24.2 \\
\hline Close to waist & 11.8 \\
\hline Head \& close to waist & 11.4 \\
\hline Close to waist \& hand & 0.9 \\
\hline
\end{tabular}

A questionnaire was prepared for calculating the percentage of mode in which the subjects like to carry water. And it was observed that out of 20 subjects studied, the most commonly adopted mode of water carrying was the head mode (51.7\%) and the least adopted was the waist mode (Table 2). It was further observed that women were also carrying water by combined modes like head and close to waist, and close to waist and hand mode. In this study only the three major modes viz. head, shoulder and waist modes were considered for the physiological analysis of the subjects.

\subsubsection{Work Terrain}

The work plane for water carrying activity was mostly horizontal except in certain cases where small slopes had to be encountered by the ladies. Paths were well defined but the passages were too narrow at certain points allowing only one person to pass through at a time.

\subsubsection{Walking Speed, Time spent, Distance travelled}

The problem of shortage of drinking water is very acute for majority of the low income group and women spend 3-4 hrs. a day in fetching water, having to walk for a long distances. The average speed of walking as observed for the WCW was 3.1 $\mathrm{km} . \mathrm{hr}^{-1}$ during onwards journey of fetching water, while the average walking speed obtained by the WCW during backward journey was $3.5 \mathrm{~km} \cdot \mathrm{hr}^{-1}$, slightly higher. This higher speed might be due to several reasons like 1) availability of water during morning for limited hours, 2) good number of people waiting in a queue to get water, 3) because she carried a load and wanted to ease herself by finishing the task as early as possible. Based on the field study same speed was selected for the laboratory simulation. On an average they fetched 22 vessels of water daily in summer (16 in morning and 6 in the evening). She spent 6-7 minute per trip to fetch water to home. Hence the time spent on fetching was varying from 132-154 minutes carrying load of 20-30 kg per trip. The approximate distance traveled per cycle of fetching water was about $0.30 \mathrm{~km}$. This depicts that she had to travel about $6.6 \mathrm{~km}$. in a day only for fetching water.

\subsubsection{Physiological stress}

For Physiological stress of subjects was determined on the basis of various parameters like average and peak heart rate, energy expenditure, maximum volume of oxygen while performing the activity. The individual heart rate was calculated from Computerized Holter Electrocardiogram system (SCHILLER). Each subject's resting HR was assessed from her ECG recording. The average resting, starting, working and return heart rates (beats. $\mathrm{min}^{-1}$ ) in different modes of water carrying in the field are shown in figure 1 . The maximum working heart rate was observed in case of head $128.7( \pm 14.02)$ beats. $\min ^{-1}$ followed by the waist mode 128.2 $( \pm 14.26)$ beats. $\mathrm{min}^{-1}$ and shoulder mode $118.3( \pm 12.31)$ beats. $\mathrm{min}^{-1}$ respectively. It was observed that the most commonly adopted mode was the head mode. Load of 20-30 $\mathrm{kg}$ was carried on the head for longer distances at a speed of $3.5 \mathrm{~km} . \mathrm{hr}^{-1}$. The women did not carry such heavy loads by shoulder or waist modes for long distances.

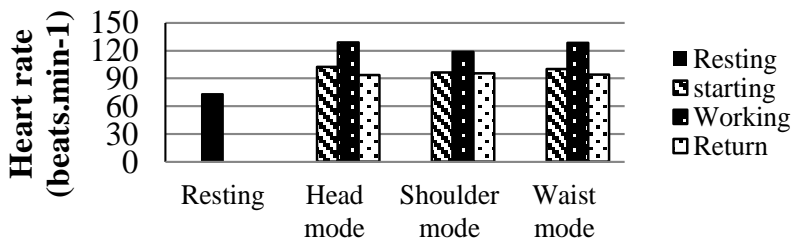

Activities

Fig 1: Average resting, starting, working and return heart rate (beats. $\mathrm{min}^{-1}$ ) in different modes of water carrying in field. 
Measurement of Physiological stress was calculated with the help of equations given below:

$\mathrm{O}_{2}$ consumption $\left(1 . \mathrm{min}^{-1}\right)=0.01095 \times \mathrm{HR}\left(\right.$ beats. $\left.\mathrm{min}^{-1}\right)-$ $0.61694 r^{2}-0.983$

Where, $\mathrm{HR}=$ Heart Rate, $\mathrm{r}^{2}=$ correlation coefficient

Energy expenditure $(\mathrm{kj} / \mathrm{min})=0.159 \times \mathrm{AHR}-8.72$

Where, AHR $=$ Average Heart Rate

The energy expenditure for three different modes worked out to be $29.15,26.98$ and $29.25 \mathrm{KJ} . \mathrm{min}^{-1}$ for head, shoulder and waist mode respectively. But the maximum volume of oxygen for the 3 modes was calculated as $54.1,46.7$ and $54.1 \% \mathrm{VO}_{2}$ max for the head, shoulder and the waist mode. The load carried for all three modes ranged from $20-30 \mathrm{~kg}$ at a walking speed of $3.5 \mathrm{~km} . \mathrm{hr}^{-1}$. The average working heart rates in the field for different loads are shown in Table 3.

Table 3. Average working heart rate in the field while carrying different modes of load.

\begin{tabular}{|c|c|c|c|c|}
\hline \multirow{2}{*}{ Mode } & \multirow{2}{*}{$\begin{array}{l}\text { Average } \\
\text { load } \\
\text { carried } \\
(\mathrm{kg})\end{array}$} & \multirow{2}{*}{$\begin{array}{c}\text { Avearge } \\
\text { heart rate } \\
\left(\text { beats.min }{ }^{-1}\right)\end{array}$} & \multicolumn{2}{|c|}{$\begin{array}{c}\mathrm{O}_{2} \text { consumption } \\
\text { (estimated) }\end{array}$} \\
\hline & & & $\left(1 . \mathrm{min}^{-1}\right)$ & $\begin{array}{c}\% \mathrm{VO}_{2} \\
\max \end{array}$ \\
\hline Head & $20-30$ & 129.6 & 0.792 & 54.1 \\
\hline Shoulder & $20-30$ & 117.9 & 0.686 & 46.7 \\
\hline Waist & $20-30$ & 128.5 & 0.790 & 54.1 \\
\hline
\end{tabular}

After the field study the subjects were asked to perform the water carrying activity in the laboratory at the same speed for the load range of $10-30 \mathrm{~kg}$ with all the three mode of carrying and the Physiological responses were noted. Subjects were then asked to carry loads for head, shoulder and waist mode. But the subjects were comfortable only in head mode for carrying this range of load. So that for shoulder mode data was recorded only for $10-25 \mathrm{~kg}$ and $10-20 \mathrm{~kg}$ for waist mode (Table 5). Prior to carry load physiological responses of the subjects were noted at $0 \mathrm{~kg}$ load by walking on treadmill (3.5 $\mathrm{km} \cdot \mathrm{hr}^{-1}$ ) and it was observed that Heart rate was 104.2 beats. $\mathrm{min}^{-1}$ and $\mathrm{O}_{2}$ uptake was $38 \% \mathrm{VO}_{2}$ max, which indicates that even at $0 \mathrm{~kg}$ workload the physiological cost to perform the job by the WCW group, was strenuous because of high walking speed. In case of head mode minimum energy expenditure was observed at $10 \mathrm{~kg}$ load demanding $\mathrm{O}_{2}$ consumption of $38.62 \% \mathrm{VO}_{2}$ max. While carrying $30 \mathrm{~kg}$ load on head the $\mathrm{O}_{2}$ consumption increased to $64.56 \% \mathrm{VO}_{2}$ max.

In case of shoulder mode the minimum $\mathrm{O}_{2}$ uptake was observed to be $47.05 \% \mathrm{VO}_{2}$ max at $10 \mathrm{~kg}$ while the maximum was $61.75 \% \mathrm{VO}_{2}$ max at $25 \mathrm{~kg}$ and the highest $\mathrm{O}_{2}$ uptake $\left(62.55 \% \mathrm{VO}_{2} \max \right)$ for $15 \mathrm{~kg}$ workload. This might be due to the higher subjective variations observed for that load. Similarly in case of waist mode the minimum $\mathrm{O}_{2}$ consumption (48.66\% $\mathrm{VO}_{2} \max$ ) was observed for $10 \mathrm{~kg}$ and maximum $\left(63.02 \% \mathrm{VO}_{2} \max \right)$ in the case of $20 \mathrm{~kg}$ load.

According to Maritz [15] the working heart rate of 105 beats $\min ^{-1}$, with a range of 95 to 115 beats $\min ^{-1}$ would be accepted for $8 \mathrm{~h}$ industrial work shift. Brouha [5] re-stated that the working heart rate should not exceed 110 beats $\min ^{-1}$ otherwise there is a chance of cumulative fatigue. It was also concluded in a study by Ayoub and mital [3] on manual material handling that the value of $\mathrm{VO} 2$ max should not be exceeding $33 \% \mathrm{VO}_{2}$, which cause cardiovascular strain
Table 4. Physiological responses of women carrying water in different loads.

\begin{tabular}{|c|c|c|c|c|}
\hline Load (kg) & $\begin{array}{c}\text { Heart rate } \\
\text { (beats.min } \\
\text { 1) }\end{array}$ & & $\begin{array}{c}\text { Energy } \\
\text { expenditure } \\
\left(\text { kj.min }^{-1}\right)\end{array}$ & $\begin{array}{c}\% \\
\mathrm{VO}_{2} \\
\max \end{array}$ \\
\hline 0 & 104.2 & \pm 12.98 & 11.48 & 38.0 \\
\hline \multicolumn{5}{|l|}{$\begin{array}{l}\text { Head } \\
\text { mode }\end{array}$} \\
\hline 10 & 116.2 & \pm 13.78 & 11.98 & 38.62 \\
\hline 15 & 119.2 & \pm 10.6 & 12.04 & 43.24 \\
\hline 20 & 126.9 & \pm 11.95 & 15.94 & 51.65 \\
\hline 25 & 133.1 & \pm 14.20 & 17.42 & 57.02 \\
\hline 30 & 133.8 & & 19.75 & 64.56 \\
\hline \multicolumn{5}{|l|}{ Shoulder } \\
\hline 10 & 130.7 & \pm 9.15 & 14.20 & 47.05 \\
\hline 15 & 145.3 & \pm 14.22 & 19.42 & 62.55 \\
\hline 20 & 145.8 & \pm 8.01 & 16.50 & 53.70 \\
\hline 25 & 156.9 & \pm 25.62 & 19.00 & 61.75 \\
\hline \multicolumn{5}{|l|}{ Waist } \\
\hline 10 & 129.8 & \pm 10.12 & 15.02 & 48.66 \\
\hline 15 & 148.2 & \pm 14.23 & 17.98 & 60.20 \\
\hline 20 & 156.2 & \pm 8.68 & 18.98 & 63.02 \\
\hline
\end{tabular}

Results shown in Table 3 and 4, clearly identify that activity of carrying water is strenuous because the values of heart rate, energy expenditure and $\% \mathrm{VO}_{2}$ max is more than the recommended safe limits, which in turn lead to the early onset of fatigue and the strong likelihood of musculoskeletal and cardiovascular strain. So, if an ANN model is developed for classifying the physiological risk of women carrying water in high and low risk category then it would be very helpful in preventing the WCW of the risk of MSDs.

\subsection{Artificial Neural Network}

An Artificial Neural Network (Neural Net or just ANN for short) is a collection of large numbers of processing elements, called nodes (or artificial neurons). In neural computing, mathematical processing units (neurons) are linked together by weighted connections. Each neuron processes its weighted inputs according to its activation function, and its output is then connected to the inputs of the next layer of neurons. Every neural network consists of three types of layers: input layer, hidden layers and output layer. The number of neurons in the input layer is equal to the number of input variables. The hidden layer allows the model to handle the non-linearity and complexity of relationship of variables. There is no general rule to determine the number of hidden layers and neurons in hidden layer(s). Furthermore, there are two kinds of output; actual and target. Actual output refers to the output of the neural network and the Target is the desired output which the ANN is trained to recognize. The difference between the actual output and the desired output is the network error. The neural network has the ability to learn from the experimental data (for gaining knowledge) expressed by inter-unit connection strengths (weights) and can make the knowledge available for later use. By allocating appropriate values to the weights, an Artificial Neural Network (ANN) can perform complicated operations on its inputs. ANN models require to be trained with acceptable accuracy before being used for data analysis. Learning process in ANN models 
is accomplished through special training algorithms that are developed to mimic the learning mechanism of biological systems [7, 24].

\subsubsection{Back Propagation Neural Networks}

One of the most commonly used training algorithms for ANN models in OSH research is feedforward backpropagation [23, 24]. In this type of model, the output variable is a function of all nodes in the hidden layer, and each node in the hidden layer is a function of input variables. No interaction is allowed between nodes of the same layer. The hidden layer allows the model to handle the non-linearity and complexity of relationship of variables. This method is easy to understand and easy to program. In this approach, the error is propagated backwards according to the delta rule [13]. One way to adjust weights in backpropagation algorithm is to use gradient descent learning rule, which, ideally, requires infinitesimal changes in the connection weights and is called Delta Rule. The input and hidden nodes' weights will be adjusted based on the error between the estimated during the training phase. ANN models use about $70 \%$ of the same data sets numerous times (up to several hundred) for training purposes, output and actual output during which the weights get updated repeatedly until the error level reaches a predetermined and acceptable level. Each usage of the data set is called epoch. This algorithm can be expressed succinctly in the form of a pseudo-code as given below:

1. Pick a rate parameter $R$.

2. Until performance is satisfactory.

For each sample input

Compute the resulting output.

Compute $\beta$ for nodes in the output layer using

$\beta z=D z-O z$

Where D represents the desired output and O represents the actual output of the neuron

Compute $\beta$ for all other nodes using

$\beta_{\mathrm{j}}=\sum_{\mathrm{k}} \mathrm{W}_{\mathrm{j} \rightarrow \mathrm{k}} \mathrm{O}_{\mathrm{k}}\left(1-\mathrm{O}_{\mathrm{k}}\right) \beta_{\mathrm{k}}$

Compute weight changes for all weights using

$\Delta \mathrm{W}_{\mathrm{i} \rightarrow \mathrm{j}}=\mathrm{rO}_{\mathrm{i}} \mathrm{O}_{\mathrm{j}}\left(1-\mathrm{O}_{\mathrm{j}}\right) \beta_{\mathrm{j}}$

Add up the weight changes for all sample inputs and change the weights.

\subsubsection{Levenberg - Marquardt (LM) \\ Approximation}

The standard BP algorithm suffers from the serious drawbacks of slow convergence and inability to avoid local minima. Therefore, BP with Levenberg - Marquardt (LM) approximation is used in this work. LM learning rule uses an approximation of the Newton's method to get better performance [17]. This technique is relatively faster but requires more memory. The LM update rule is:

$$
\Delta \mathrm{W}=\left(\mathrm{J}^{\mathrm{T}} \mathrm{J}+\mu \mathrm{I}\right)^{-1} \mathrm{~J}^{\mathrm{T}} \mathrm{e}
$$

Where $\mathrm{J}$ is the Jacobean matrix of derivatives of each error to each weight $\mu$ is a scalar and $\mathrm{e}$ is an error vector. If the scalar is very large, the above expression approximates the Gradient Descent method; while it is small the above expression becomes the Gauss - Newton method. The Gauss Newton method is faster and more accurate near error minima. Hence, the aim is to shift towards the Gauss - Newton as quickly as possible. The $\mu$ is decreased after each successful step and increased only when the step increases the error.

\subsubsection{Experimental Data for Model Development}

Based on the preference of the subjects $(51.7 \%)$ and maximum load lifted $(30 \mathrm{~kg})$, head mode was selected for the development of ANN model. The data was collected for training and testing neural network, from the selected subjects by experimentation in laboratory. Their physiological stress were divided into two groups; high and low risk work based upon the factors load carried, age, ponderal index, walking speed and working hours as the changes in the values of these factors influence the physiological stress. A total of 62 different data sets of physiological stress were recorded for the different values of the input variables.

\subsubsection{Training, Test and validation Datasets}

Out of 62 different data sets, 40 data sets (27 high risk and 13 low risk) randomly selected were used for the training and the remaining 22 data sets ( 14 high and 8 low risk jobs) were used for the testing of model (Table 5 and 6). The purpose of breaking the data into training set and test set was to provide a check on a real-world situation. The training set was used to train the neural network, a procedure that reduces the least square error between the correct response and the actual response until an acceptable overall error is reached and the test set was used to validate that the network has been trained appropriately, and that it is able to generalize the relationships between inputs and outputs, and provide the desired response in those cases which had not been used during the training process.

\subsubsection{Normalization of Training data}

The values of the input variables for male and female workers are given in Table 5 and 6 . To prevent network's saturation [25], these variables were normalized in between [0.1 0.9 ] by a programme written in Matlab. The output variable (risk of load carrying) takes values of 0.9 or 0.1 for high and low risk work, respectively.

\subsubsection{Network training and development of model}

The purposed neural network model used for the training contained 5 input variables which were as follows: (1) Load (2) Age (3) Ponderal Index (4) Walking Speed (5) Working Hours. These input variables were connected with two hidden layers and consisted of 5 neurons in each hidden layer. Hidden layers were then connected with single output layer neuron which classified the physiological risk (High/Low) or desired response of the network. The network was trained in MATLAB environment software programmed by exploiting Neural Network Toolbox model version R.2010.a. This software is chosen due to its capabilities and ability to provide solutions in technical computing. Among various training algorithm available, Levenberg-Marquardt (LM) training function was selected because it has the fastest convergence ability [17].

The learning rate and the momentum used in training were 0.1 for all comfort indicators. The learning rate is a control parameter, which affects the changing of weights. The bigger learning rate causes larger weight changes by each iteration. The momentum is a control parameter that effects the changing of weights. The greater the momentum, the more the current weight change is affected by the weight change that took place during the previous iteration. 


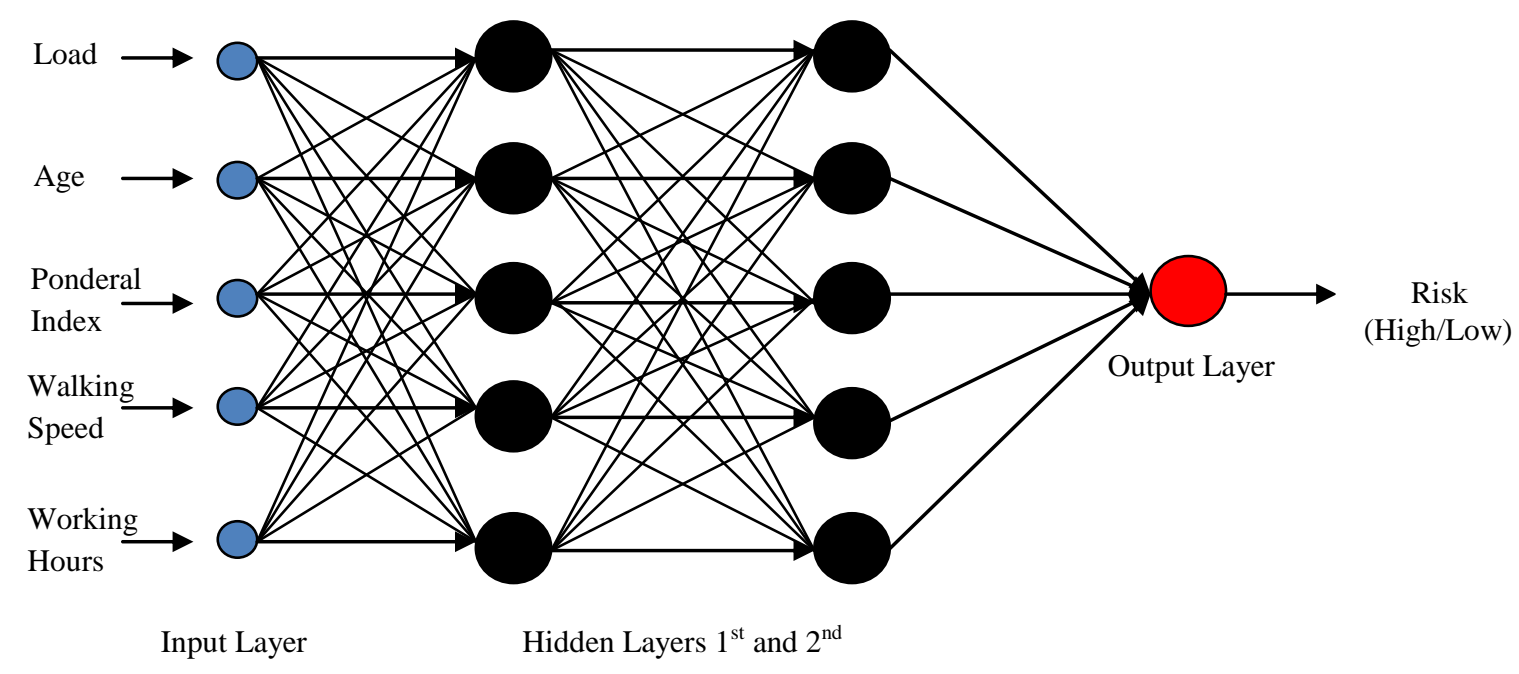

Fig 2: The Architecture of the proposed artificial neural network model.

Table 5. Randomly selected jobs for low risk of LBDs used for network's training

\begin{tabular}{|c|c|c|c|c|c|c|}
\hline S. No. & $\begin{array}{c}\text { Load } \\
(\mathrm{kg})\end{array}$ & Age & $\begin{array}{l}\text { Ponderal } \\
\text { Index }\end{array}$ & $\begin{array}{c}\text { Walking } \\
\text { Speed }\end{array}$ & $\begin{array}{c}\text { Working } \\
\text { Hours }\end{array}$ & $\begin{array}{c}\text { Physiological } \\
\text { Stress }\end{array}$ \\
\hline 1. & 40 & 32 & 23.2 & 2.6 & 5 & High \\
\hline 2. & 36 & 28 & 23.2 & 2.7 & 6 & High \\
\hline 3. & 34 & 31 & 24.1 & 2.8 & 6 & High \\
\hline 4. & 32 & 23 & 22.4 & 2.6 & 5 & High \\
\hline 5. & 31 & 32 & 23.1 & 2.5 & 6 & High \\
\hline 6. & 31 & 34 & 23.4 & 2.8 & 5 & High \\
\hline 7. & 30 & 41 & 23.2 & 3.3 & 6 & High \\
\hline 8. & 28 & 28 & 22.8 & 2.9 & 6 & High \\
\hline 9. & 28 & 26 & 24.0 & 2.7 & 5 & High \\
\hline 10. & 27 & 26 & 23.3 & 2.9 & 6 & High \\
\hline 11. & 27 & 33 & 23.0 & 3.7 & 6 & High \\
\hline 12. & 27 & 24 & 23.8 & 3.1 & 6 & High \\
\hline 13. & 27 & 25 & 23.2 & 1.9 & 6 & High \\
\hline 14. & 26 & 25 & 23.3 & 3.0 & 5 & High \\
\hline 15. & 26 & 24 & 22.6 & 3.2 & 6 & High \\
\hline 16. & 26 & 31 & 23.5 & 3.1 & 6 & High \\
\hline 17. & 26 & 25 & 22.6 & 3.2 & 5 & High \\
\hline 18. & 26 & 25 & 23.4 & 3.4 & 5 & High \\
\hline 19. & 23 & 38 & 23.5 & 3.1 & 6 & High \\
\hline 20. & 22 & 33 & 22.4 & 2.7 & 6 & High \\
\hline 21. & 22 & 43 & 22.7 & 2.9 & 6 & High \\
\hline 22. & 22 & 38 & 23.7 & 2.8 & 5 & High \\
\hline 23. & 21 & 26 & 22.9 & 2.5 & 5 & High \\
\hline 24. & 20 & 33 & 23.1 & 3.0 & 5 & High \\
\hline 25. & 19 & 44 & 23.1 & 2.8 & 6 & High \\
\hline 26. & 18 & 40 & 23.0 & 3.1 & 6 & High \\
\hline 27. & 18 & 43 & 22.7 & 2.2 & 5 & High \\
\hline 28. & 28 & 23 & 22.9 & 2.8 & 4 & Low \\
\hline 29. & 19 & 22 & 22.8 & 2.7 & 4 & Low \\
\hline 30. & 18 & 27 & 23.8 & 3.0 & 6 & Low \\
\hline 31. & 17 & 27 & 23.2 & 3.0 & 6 & Low \\
\hline 32. & 16 & 26 & 22.5 & 2.2 & 6 & Low \\
\hline 33. & 16 & 28 & 23.3 & 3.1 & 5 & Low \\
\hline 34. & 16 & 27 & 23.1 & 2.6 & 4 & Low \\
\hline 35. & 16 & 28 & 23.3 & 3.1 & 5 & Low \\
\hline 36. & 15 & 23 & 23.8 & 2.8 & 5 & Low \\
\hline 37. & 14 & 34 & 23.1 & 3.1 & 5 & Low \\
\hline 38. & 13 & 24 & 24.1 & 3.6 & 5 & Low \\
\hline 39. & 12 & 42 & 23.2 & 2.8 & 6 & Low \\
\hline 40. & 12 & 47 & 22.9 & 2.8 & 5 & Low \\
\hline
\end{tabular}




\section{NEURAL NETWORK RESULTS \& DISCUSSION \\ 4.1 Network performance}

Table 6. The percentage variation in experimental and ANN model results

\begin{tabular}{|c|c|c|c|c|c|c|c|l|}
\hline S. No. & $\begin{array}{c}\text { Load } \\
(\mathbf{k g})\end{array}$ & Age & $\begin{array}{c}\text { Ponderal } \\
\text { Index }\end{array}$ & $\begin{array}{c}\text { Walking } \\
\text { Speed }\end{array}$ & $\begin{array}{c}\text { Working } \\
\text { Hours }\end{array}$ & $\begin{array}{c}\text { Physiological } \\
\text { Stress }\end{array}$ & $\begin{array}{c}\text { Model } \\
\text { Prediction }\end{array}$ & Error \\
\hline 1. & 34 & 25 & 22.4 & 2.9 & 6 & High & High & -0.004 \\
\hline 2. & 32 & 43 & 23.4 & 3.3 & 5 & High & High & 0 \\
\hline 3. & 31 & 34 & 22.8 & 2.6 & 6 & High & High & -0.003 \\
\hline 4. & 29 & 23 & 23.5 & 2.7 & 6 & High & High & 0 \\
\hline 5. & 28 & 26 & 22.6 & 2.9 & 5 & High & High & 0 \\
\hline 6. & 27 & 26 & 25.1 & 2.7 & 6 & High & High & 0.012 \\
\hline 7. & 26 & 32 & 23.1 & 3.1 & 6 & High & High & 0 \\
\hline 8. & 26 & 41 & 23.5 & 1.8 & 5 & High & High & 0 \\
\hline 9. & 23 & 24 & 23.2 & 3.2 & 6 & High & High & 0 \\
\hline 10. & 22 & 33 & 22.4 & 3.2 & 6 & High & High & 0 \\
\hline 11. & 21 & 20 & 23.3 & 2.3 & 6 & High & High & 0.035 \\
\hline 12. & 20 & 43 & 24.1 & 2.9 & 5 & High & High & 0.233 \\
\hline 13. & 19 & 43 & 23.2 & 2.8 & 4 & High & High & 0 \\
\hline 14. & 18 & 41 & 23.2 & 3.2 & 6 & High & High & 0 \\
\hline 15. & 21 & 22 & 22.2 & 2.4 & 5 & Low & High & -7.999 \\
\hline 16. & 18 & 36 & 23.7 & 2.8 & 5 & Low & Low & 0 \\
\hline 17. & 17 & 34 & 23.2 & 2.5 & 6 & Low & Low & -0.159 \\
\hline 18. & 16 & 22 & 22.3 & 3.1 & 5 & Low & Low & -0.005 \\
\hline 19. & 15 & 28 & 23.1 & 3.4 & 5 & Low & Low & 0 \\
\hline 20. & 14 & 30 & 23.6 & 3.5 & 5 & Low & Low & 0 \\
\hline 21. & 13 & 40 & 23.1 & 2.6 & 4 & Low & Low & 0 \\
\hline 22. & 12 & 37 & 23.1 & 3.1 & 5 & Low & Low & 0 \\
\hline
\end{tabular}

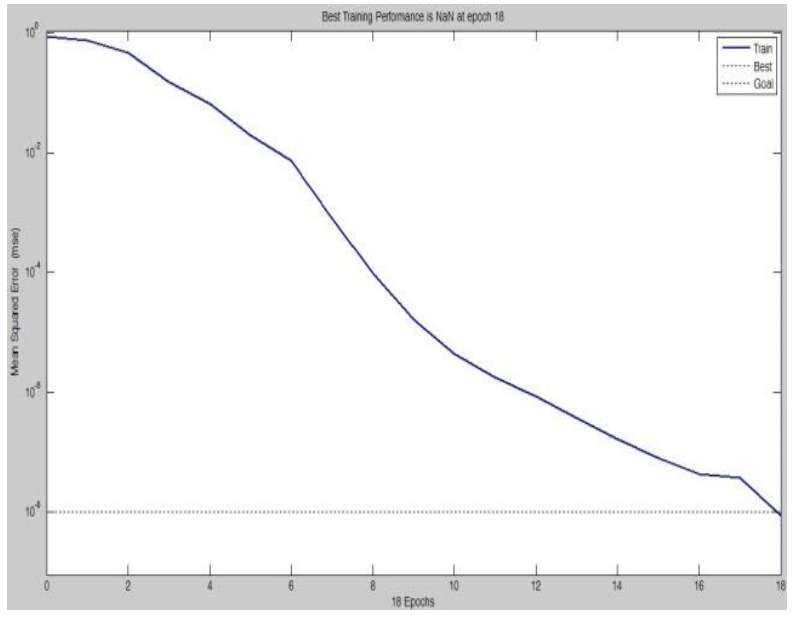

Fig 3: Training error versus number of training cycles (Epochs)

The developed diagnosis system classified 21 out of 22 cases correctly $(95.45 \%)$. For 8 low risk jobs, only 1 job was incorrectly classified as high risk job, in contrast all high risk jobs were correctly classified. The simulated results of ANN model are shown in Table 6 with the corresponding errors which are acceptable in range. Results showed a great promise of Neural Network model in predicting physiological stress in WCW based on five input parameters and it was also suggested, LM training for back propagation $\mathrm{NN}$ give good prediction and are validated with experimental values as indicated in Table 6. Most of the subjects used in this study were local habitual staying in village of Haryana for more than 15 yrs. or since birth and has a literacy of $20 \%$. They are not aware about their health being and always involve some kind of household activities After the whole day job women always complain about the exertion, and pain in different parts of the body but they never take it seriously which leads them to fatigue and exertion. From the physiological study it was found that values of physiological parameters increases with the increase of load and it was observed that the values of these parameters were high in case of waist and shoulder in contrast to head mode. But in this study only the head mode was considered due to preference of the subjects. So, such type of expert system can be an aid for WCW whose nature of job is drudgery.

ANN captures the intricate relationship among various process parameters and can be integrated readily into an existing environment. Table 7 shows a comparison between results of past studies models and the current study model in terms of accuracy in classifying physiological stress in Low and High risk and the current study has an edge over the past studies, as it provides a higher proportion of correct classifications (95.45\%) than other previous models.

\section{CONCLUSION}

Results from this study evidently prove that developed ANN model is reliable to predict physiological stress and produce higher accuracy than previous models. MSDs are challenging problems and there is still lot of work needs to be done in this area. The proposed system provides a faster response and a reduced cost compared to human experts. Such a system could be very useful in hazard analysis and injury prevention from manual carrying of loads. Results of the study suggest that LM training is faster than the general delta rule and it needs less input pattern to training than the other one. If larger and 
Table 7. Comparison of the results of previous studies and current approach.

\begin{tabular}{|l|l|l|l|l|}
\hline \multicolumn{1}{|c|}{ NIOSH [18] } & \multicolumn{1}{|c|}{ NIOSH [19] } & \multicolumn{1}{c|}{ Zurada [25] } & \multicolumn{1}{c|}{ Asensio-Cuesta [2] } & \multicolumn{1}{c|}{ Current Study } \\
\hline $\begin{array}{l}\text { Correctly classified } \\
91 \% \text { of low risk jobs, } \\
\text { but only 10\% of the } \\
\text { high risk jobs }\end{array}$ & $\begin{array}{l}\text { Correctly classified } \\
55 \% \text { of the low risk } \\
\text { jobs and 73\% of the } \\
\text { high risk jobs. }\end{array}$ & $\begin{array}{l}\text { Correctly classified } \\
\text { Industrial jobs for } \\
\text { about } 75 \% \text { (with both } \\
\text { low and high risk of } \\
\text { LBDs) }\end{array}$ & $\begin{array}{l}\text { Correctly classified } \\
\text { highly repetitive } \\
\text { lifting industrial jobs } \\
\text { about 87\%(with both } \\
\text { low and high risk of } \\
\text { LBDs) }\end{array}$ & $\begin{array}{l}\text { WCW jobs 95.45\% } \\
\text { high risk of MSDs) }\end{array}$ \\
\hline
\end{tabular}

more homogenous data sets are provided than it will result in better training of ANN models with smaller errors and biases. Future work will focus on validation of the ANN architecture, and consider utilization of other input variables for the modeling, including different modes of load carrying, individual characteristics of the WCW, and the work stressors such as biomechanical and psychosocial.

\section{REFERENCES}

[1] Adams, M., Bogduk, N., Burton, K. and Dolan, P. 2002. The Biomechanics of back pain. Edinburgh: Churchill Livingstone.

[2] Asensio-Cuesta, S., Diego-Mas, J.A. and AlcaideMarzal, J. 2010. Applying generalized feedforward neural networks to classifying industrial jobs in terms of risk of low back disorders. International journal of Industrial Ergonomics, 40, 629-635.

[3] Ayoub, M. M. and Mital, A. 1989. Manual Materials Handling. London: Taylor and Francis.

[4] Badve, S. A., Bhojraj, S., Nene, A., Raut, A. and Ramakanthan, R. 2010. Occipito-Atlanto-Axial Osteoarthritis: A cross sectional clinico-radiological prevalence study in high risk and general population. Spine, 35, 434-438.

[5] Brouha, L., 1967. Physiology in Industry. Pergamon Press, Oxford.

[6] Buckle, P. W. and Devereux, J. J. 2002. The nature of work-related neck and upper limb musculoskeletal disorders. Appl Ergon, 33, 207-217.

[7] Cheng, B. and Titterington, D. M. 1994. Neural networks: a review from statistical perspective. Stat Sci; 9, 2-54.

[8] Dufault, A. 1990. How water carrying affects women's health. Community Health and Sanitation, Intermediate Technology publication, 30-35.

[9] Geere, J. L., Hunter, P. R., Jagals, P., 2010. Domestic water carrying and its implications for health: a review and mixed methods pilot study in Limpopo Province, South Africa. Environmental Health, 9:52, 1-13.

[10] Gleick, P. H. 1996. Basic Water Requirements for Human Activities: Meeting Basic Needs. Water International, 21, 83-92.

[11] Jindal, A. 1992. Housing Needs in Content of Rural Women. M.Sc. Thesis, Haryana Agricultural University, Hisar, 1-165.

[12] Joosab, M., Torode, M. and Rao, P.V. 1994. Preliminary findings on the effect of load carrying to the structural integrity of the cervical spine. Surg Radio Anat, 16, 393 398.

[13] Kantardzic, M. 2003. Data Mining Concepts Models Methods and Algorithms. Wiley Interscience Press.

[14] Kapoor, A. 2003. Water, work and women in rural India. World resources institute, 1(8).

[15] Lloyd, R., Parr, B., Davies, S. and Cooke, C. 2010. Subjective perceptions of load carriage on the head and back in Xhosa women. Appl Ergon, 41, 522-529.

[16] Maritz, J. S., Morrison, J. F., Peters, J., Strydon, N. B., Wyndham, C. H., 1961. A practical method of estimating an individual's maximum oxygen uptake. Ergonomics 4, 97-122.

[17] More, J. J. 1977. The Levenberg - Maquardt Algorithm: Implementation and theory. Numerical Analysis, G. A. Watson (Ed.), Lecture Notes in Mathematics, Springer Verlag, 630, 105-116.

[18] NIOSH, 1981. Work practices guide for manual lifting. DHHS (NIOSH) pub. No. 81-122. Cincinnati, OH, US Department of Health and Human Services.

[19] NIOSH, 1991. Work practices guide for manual lifting. DHHS (NIOSH) pub. No. 94-107. Cincinnati, OH, US Department of Health and Human Services.

[20] Report of the United Nations High Commissioner for Refugees. 1992. United Nations, New York.

[21] Simms, J. 1994. Anthology on Women Health and environment. World Health Organization.

[22] Sultana, F. 2009. Fluid lives: subjectivities Gender and water in rural Bangladesh. Gender, Place \& Culture, 16, 427-444.

[23] Yousefizadeh, H. and Zilouchian, A. 2001. Neural network structures. In Zilouchian A and Jamshidi M, editors. Intelligent control systems using soft computing methodologies. Boca Raton, FL: CRC Press, 39-66.

[24] Zilouchian, A. 2001. Fundamentals of neural networks. In Zilouchian A and Jamshidi M, editors. Intelligent control systems using soft computing methodologies. Boca Raton, FL: CRC Press, 17-38.

[25] Zurada, J., Karwowski, W. and Marras, W. S. 1997. A neural network-based system for classification of industrial jobs with respect to risk of low back disorders due to workplace design. Applied Ergonomics, Elsevier, 28(1), 49-58. 